\title{
Dystocia in camelids: The causes and approaches of management
}

\author{
Govind Narayan Purohit
}

Department of Veterinary Gynecology and Obstetrics, College of Veterinary and Animal Science, Rajasthan University of Veterinary and Animal Science, Bikaner, India; gnpobs@gmail.com

Received 9 August 2011; revised 18 September 2011; accepted 3 October 2011

\begin{abstract}
Dystocia in the camelids is rare, however the exceptionally long neck and the fetal extremities predispose to flexion of these as a common cause of dystocia. A prolonged ( $<2 \mathrm{hr}$ ) second stage of labor, bloody vaginal discharge or colic is the frequent sign of dystocia. The maternal causes of dystocia for camelids include uterine torsion, pelvic immaturity, uterine inertia and cervical dilation failure, whereas the fetal causes described are fetal malpostures and rarely fetal monsters like Schistosoma reflexus and Perosomus elumbis or fetal dropsical conditions such as hydrocephalus. Dromedary camels must be restrained in a sternal recumbency for examination and vicious animals must be given xylazine (0.25 - $2.2 \mathrm{mg} / \mathrm{Kg}$ IM or IV). South American camelids may be restrained by using either $x y-$ lazine or butarphanol $(0.5-0.1 \mathrm{mg} / \mathrm{Kg} \mathrm{IM})$. Uterine torsion is much more common in llamas and alpacas whereas it is infrequent in the dromedary camel. The methods of dystocia correction by using mutations, fetotomy and cesarean section are described.
\end{abstract}

Keywords: Camel; Cesarean; Dystocia; Fetal; Maternal

\section{INTRODUCTION}

The gestation length is highly variable in camelids varying from 315 to 440 days in dromedary camel [1] and 330 to 365 days in llamas and alpacas [2]. Parturition in camelids is a unique process with a variable first stage of labor (2 - $6 \mathrm{hr}$ ) and short second stage of labor (10 $45 \mathrm{~min})$. The time for the complete process of parturition reported is $373.9 \pm 38.2 \mathrm{~min}[3,4]$. The mechanisms of parturition have been previously described [5-12]. Because of the exceptionally long neck and limbs and the fact that nearly all fetuses are born in an anterior longitu- dinal presentation $[7,13,14]$ a possibility of limb/neck deviation always exists. This review analyzes the reported causes of dystocia in camelids and their management.

\section{INCIDENCE}

Breeding dromedary camels are frequently kept by pastoralists at many places. Farmers in some countries keep female dromedaries for agricultural use and breeding is seldom performed. Only few breeding farms exist in a few countries where from the incidence of difficult births can be observed to be low (0.4\%) [15] over the entire calving. The incidence of dystocia is low in the camels; however because of the exceptionally long neck and extremities when it occurs, it is difficult to manage. The incidence reported varies from $0.4 \%$ [15] to $4.6 \%$ [16]. The incidence reported for llamas vary between $2 \%$ to 5\% [17-21]. Data from 1660 births in alpacas (in South America) recorded an incidence of only $1.6 \%$ whereas data of 234 llama births demonstrated an incidence of only $0.4 \%$ [22]. The incidence in Bactrian camel $[23,24]$ is exceptionally low and not reported for large number of births. In most cases of dystocia, intervention occurs during the second stage of labor after observation of a failure of normal progression of the first stage of labor [16].

\section{DIAGNOSIS OF DYSTOCIA}

Early diagnosis of dystocia is important; however, many times the diagnosis is very late and frequently noticed only when the limbs of the fetus are protruding through the birth canal and the animal straining vigorously. At organized farms, camels are monitored frequently around the due dates for parturition, but this is not routine for the pastoralists as they keep no records. The most important sign of dystocia is the increased duration of the second stage of labor. Dystocia should be suspected if the first stage or second stage of labor exceeds 6 and 2 hours respectively. In addition, the dam may show signs of distress frequently alternating be- 
tween standing and sitting with frequent side to side rolling and excessive straining. Many dromedary females will show diarrhea and frequent vocalization in such cases. At times, females are depressed and show no signs except slight straining and a blood stained discharge.

\section{RESTRAINT AND ANESTHESIA}

When, a problem is suspected a vaginal and rectal examination should be performed, with the animal secured in a sitting posture. Ropes must be tied on both hind and fore legs separately and a person should hold the nose rope to secure the head to avoid biting by the females. The tail should also be fastened by rope. Some animals may require sedation by IM or IV administration of xylazine. Straining may be initiated by examination, and hence examination should be gentle. It is important to evaluate the extent of dilation of the birth canal, condition of the water bags, and the disposition of the fetal limbs and head if possible, and if present in the birth canal. Because of the long limbs a deviated head may be many times beyond the approach of the obstetrician. The fetal viability should also be ascertained, but it is not uncommon to find the fetus to be dead when female camels are presented to referral centers. Obstetrical examination and manipulation can be very difficult if the birth canal is very small (Llamas, alpacas and young dromedaries) [16]. It is frequently not possible to assess the presentation, position and posture especially when camels are presented after sufficient delay. The birth canal is contracted in such cases.

\section{TYPES OF DYSTOCIA}

Although both maternal and fetal causes have been described for dystocia in the female camelids, however fetal causes are much more frequent compared to maternal causes because of the exceptionally long extremities and the neck $[25,26]$. Maternal and fetal causes of dysto- cia accounted for $43 \%$ and $57 \%$ of total cases [27]. At our referral centre fetal causes were the predominant cause of dystocia (Table 1) and similar findings were noticed elsewhere [25].

\subsection{Maternal Dystocia}

The maternal causes of dystocia described for camelids include uterine torsion in llamas [28-30] and dromedary camels [31-34], immaturity of the female [16,35], cervical dilation failure $[26,36,38]$ and rarely uterine inertia [16].

The diagnosis of uterine torsion is often difficult in dromedary camels because little changes do occur in the vagina and the palpation of the broad ligaments per rectum is difficult [25]. All the more, the therapy of uterine torsion by rolling is not readily feasible because of its large size and enormous resistance that would probably be exerted by the animal. Most reports depicting therapy of uterine torsion in dromedary camels had utilized caesarean section for treatment [31,32,37].

Uterine torsion in llamas and alpacas usually occurs near term gestation [30]. Camelids may show signs of abdominal pain or may simply lie down and appear to be depressed [2,38]. Cebra [39] reported 20 cases of uterine torsion occurring in 11 llamas and three alpacas, 19 were clockwise in direction (left uterine horn rolling dorsal to the right uterine horn) whereas another study recorded $60 \%$ of the uterine torsions to be counterclockwise [30]. Uterine torsion was corrected by rolling in eight dams, by celiotomy in seven dams, and by transvaginal manipulation in five dams [39]. Surgery is indicated if correction is not achieved within two rolling attempts. Uterine torsion usually occurs at the termination of gestation, does not have a clear age or season predisposition, and can often be corrected without surgery in llamas and alpacas [30]. Uterine torsion can reoccur in a short time in a small number of females subsequent to correction by

Table 1. Frequency of different dystocia in camelids in different reports.

\begin{tabular}{|c|c|c|c|c|}
\hline Cause of dystocia & $\begin{array}{l}\text { Proportion of cases } \\
\text { (Dromedary camel) }\end{array}$ & $\begin{array}{l}\text { Proportion of cases } \\
\text { (Lamas and alpacas) }\end{array}$ & $\begin{array}{l}\text { Proportion of cases } \\
\text { (Lamas and alpacas) }\end{array}$ & $\begin{array}{l}\text { Proportion of cases } \\
\text { (Dromedary camel) }\end{array}$ \\
\hline \multicolumn{5}{|l|}{ FETAL } \\
\hline Anterior presentation & $91.67 \%$ & & $70 \%$ & $74.07 \%$ \\
\hline Posterior presentation & $8.33 \%$ & & $30 \%$ & $25.93 \%$ \\
\hline Fetal maldisposition & $74.99 \%$ & $17.4 \%$ & & $62.96 \%$ \\
\hline Head and Neck deviation & $41.66 \%$ & & & $37.03 \%$ \\
\hline Limb flexion & $33.34 \%$ & & & $3.70 \%$ \\
\hline Fetal monster & $8.33 \%$ & & & $3.70 \%$ \\
\hline \multicolumn{5}{|l|}{ MATERNAL } \\
\hline Uterine torsion & $6.33 \%$ & $43.5 \%$ & & $14.81 \%$ \\
\hline Cervical dilation failure & $1.82 \%$ & $17.4 \%$ & & - \\
\hline Fetomaternal disproportion & $8.33 \%$ & $8.7 \%$ & & $3.70 \%$ \\
\hline Uterine inertia & - & - & - & $7.41 \%$ \\
\hline Reference & Purohit et al., 2011 & Anderson, 2009 & Bravo, 2002 & Straten, 2000 \\
\hline
\end{tabular}


rolling and the diagnosis of torsion by rectal palpation requires some experience due to smaller and thinner broad ligaments in llamas and alpacas [30]. Clinical signs may be rarely non-existent or include fever, tachycardia, tachypnea, anorexia, straining, vaginal discharge and sometimes a severe colic [30]. When the uterus cannot be corrected by rolling, when the cervix does not dilate sufficiently to deliver the fetus, or when fetal disproportion or anomalies prevent delivery of the fetus, cesarean section is indicated.

A narrow pelvis (due to untimely breeding of females), results in dystocia and necessitate a cesarean section. When there is a failure of the vulva to stretch, sufficient space would not be available for the passage of the fetal head and this can be managed by episiotomy [16] however, when this is not helpful an emergency cesarean section is suggested.

Primary uterine inertia is rarely seen in the aged dromedary camel [16] however, a recent report depicted that the incidence of primary uterine inertia was 20\% (of all maternal causes) [27]. Secondary uterine inertia is commonly possible when a fetus cannot be delivered by efforts of the dam because of fetal maldisposition.

Although abdominal and inguinal hernias are known to be existent in the camel [40-42] it has not been reported as a cause of dystocia in the camel since hernias were found to be more frequent in males. An inguinal hernia with descent of non pregnant uterus was recorded by Ramadan and Abdin Bey [42]. The possibility of hernias as maternal cause of dystocia however, cannot be ruled out in the camel.

Cervical dilation failure has rarely been reported as a cause of dystocia in the dromedary camel. Parturition induction with prostaglandin F2 alpha was done in this camel which had signs of parturition onset without cervical opening [43]. Similar findings have been observed for three alpacas. However, these animals were operated to deliver the fetuses [36]. Dystocia due to obstruction of the birth canal on account of cervical, vaginal or vulvar growths or tumors has not been reported. Although one llama developing vaginal stricture subsequent to trauma from uterine torsion was treated by carbon dioxide laser [44] but such problems causing dystocia are not found.

\subsection{Fetal Dystocia}

Dystocia of fetal origin is common in the camels. Fetal causes include fetal maldisposition, fetal dropsical conditions and fetal monsters. Feto-pelvic disproportion and monstrosities were considered rare in the camel [45]. The most frequent maldisposition in the anterior presentation is the lateral head deviation $[25,46,47]$ and carpal flexion [8]. At our referral centre 5 cases of head deviation were presented, and 4 cases were of limb flexion (Table 1).
Besides the above, forelimbs crossed over the neck (Foot nape) [34] and breech presentation have been reported both in dromedary [44] and Bactrian [23] camel. Likewise, lateral head deviation and limb flexion have been reported in South American camelids [17,18,26,28,38,48, 49].

Fetal monstrosities reported for camel include Schistosoma reflexus $[34,50]$ muscle contracture with stiffness of hind limbs and neck [51], Anencephaly [52] and Perosomus elumbis. Likewise, hydrocephalus [53] and fetal anasarca [16] are the reported fetal dropsical conditions. Fetal emphysema occurs frequently in unattended cases of dystocia with fetal death. Dystocia of fetal origin due to oversized fetus is relatively rare in camelidae [3].

\section{MANAGEMENT OF DYSTOCIA}

Animals must be in sitting position, restrained by ropes and administered xylazine as described previously. The management of dystocia in camels is relatively difficult because of the length of the fetal limbs and neck, and comparative narrowness of the birth canal especially in young dromedaries and in llamas and alpacas [16]. Not all the techniques described for dystocia correction described for cattle can be used in camels.

\subsection{Mutation}

Repulsion of the fetus is possible only to a smaller degree that too when cases are presented early. Although it has been described that repulsion can be obtained by direct manual pressure on the fetus or by using a repulsion rod [16].

It has also been mentioned that if the animal receives a tocolytic medication or epidural anesthesia, repulsion can be easily done [16]. However, in cases presented after a delay of more than 24 hours (which is usual) repulsion is extremely difficult.

Partial rotation $\left(45^{\circ}\right.$ to $\left.90^{\circ}\right)$ of the fetus has been described to be possible to correct shoulder lock (in anterior presentation) and hip lock (in posterior presentation) $[1,16]$ but this seems difficult in cases presented after delay.

Slight extension and adjustment of the extremities is possible in the camel manually, but version is impossible and also not required because no transverse pregnancy has been reported in the dromedary camels.

Forced extraction of the fetus after correction of a small degree of limb flexion or lateral head deviation is the most common procedure in camel dystocia. However, limb flexion or head deviation when attended after sufficient delay require techniques other than forced extraction. Forced extraction necessitates ample lubrication of the birth canal and should only be attempted in a fully dilated birth canal [25]. In the llama and alpaca, the dila- 
tion of birth canal is important as the passage is more fragile compared to dromedary camels $[28,48]$. Ropes and obstetrical chains are helpful in forced extraction. An obstetrical long hook used in cattle can be used to correct a smaller degree lateral head deviation in a dead fetus, if the orbit of the eye is within reach of the clinician. Greater degrees of head deviations or limb flexions are not correctable by manual means as the head or limbs are not within the reach of the clinician.

\subsection{Fetotomy}

Partial fetotomy of the head or limbs is possible in camels using a Thygesons or other fetatomes used in cattle. This creates space for manipulation and correction of the abnormality. Although fetotomy has been reported in guanaco [17] it is seldom possible in the llama and alpaca because of the small size of the pelvis, making manipulations very difficult [16]. Sometimes, similar difficulties may be encountered in young dromedary camels. Fetotomies and forced extraction can deliver dead fetuses, but, may sometimes lead to a fatal uterine hemorrhage due to injury to the birth canal and hence cesarean section must be performed [25,54].

\subsection{Cesarean Section}

Aspects of female surgery and obstetrics are poorly described for camels. In one study evaluating published literature for two decades it was found that reports on female surgery and obstetrics formed only $5.52 \%$ of the total [55]. Cesarean section in dromedary camels is often performed when sufficient delay has occurred in presentation of the animal to referral centers because at this time the fetus is usually dead and the birth canal is contracted making manipulations in the birth canal impossible. It is also usual to perform the operation in camelids when an unusual deviation of the head and neck has occurred which is beyond the approach of the obstetricians hand. Rarely an uncorrectable presentation, uterine torsion and monstrosities are an early indication for performing the operation in camelids [26,29,37,54,56]. When cesarean is performed in camels with dead putrefied fetuses, the survival of the dam is always at risk due to possible development of a fatal peritonitis. The skin sutures heal poorly in the dromedary camel and the sutures on the muscles may break due to movements of the animal predisposing to a post operative hernia. However, referral centers have no choice other than to perform the operation whilst it is known that the prognosis would be guarded when dead putrefied fetuses are present. However, with an early decision to perform the operation and with sufficient peri-operative care the survival rate of dams is good [26].

\subsubsection{Pre Operative Preparation and Anesthesia}

Pre operative fasting is not possible in camels because cesarean is most of the times an emergency. It is pertinent to care for the general condition of the patient before attempting to perform a cesarean section [39]. When the animal is dehydrated or depressed, sufficient fluid therapy and antibiotics must be given along with corticosteroids when required. This would often delay the operation by 2 to $4 \mathrm{~h}$ but is necessary. Different anesthetic combinations have been described in the past including chloral hydrate [31,57], premedication with chlorpromazine hydrochloride followed by a chloral hydrate and magnesium sulfate mixture [35], premedication with triflupromazene [32]. However, currently the use of xylazine as a sedative administered by intravenous route $[58,59,67]$ along with local infiltration anesthesia is suggested. The dose of xylazine suggested for camels is 0.25 $\mathrm{mg} / \mathrm{Kg}[58,60,61]$. A higher dose of $2.2 \mathrm{mg} / \mathrm{Kg}$ given IM has also been suggested [62]. An initial dose of 140 - 180 $\mathrm{mg}(6-8 \mathrm{ml})$ of xylazine is administered IM or IV but some dromedary camels may require repetition of the dose during the operation, sometimes even three times (450 mg) the total initial dose. Pre medication with atropine sulfate would thus be beneficial. Reversal of xylazine can be achieved using $0.125 \mathrm{mg} / \mathrm{Kg}$ of yohimbine or $1-2 \mathrm{mg} / \mathrm{Kg}$ of tolazoline [30].

Regional anesthesia of the surgical site by inverted "L" and line block (60 $\mathrm{ml}$ to $120 \mathrm{ml}$ of $2 \%$ xylocaine or lidocaine solution) with good restraint is sufficient for dromedary camels.

Anesthesia in llamas and alpacas can be achieved using combinations of xylazine as a sedative and lidocaine for local infiltration, or a combination of xylazine and lidocaine for epidural analgesia [11,63]. Recent alternatives to this include butarphanol $(0.5-0.1 \mathrm{mg} / \mathrm{Kg} \mathrm{IM}$ or SC) with lidocaine line block [38]. Alternatively, metdetomidine at the dose rate of $10-30 \mu \mathrm{g} / \mathrm{Kg}$ has also been suggested [64]. General anesthesia has been suggested for South American camelids using guaifenesin followed by intubation and maintenance with $2 \%$ halothane or isoflurane $[26,29,56]$.

\subsubsection{Operative Sites and Operative Procedure}

Two operative sites are commonly used for cesarean in the camelids; the paralumbar fossa and oblique ventrolateral. A ventral midline approach is considered to be improper due to severe postoperative complications [26, 30,38]. The left paralumbar fossa is a site on which the operation is easy to perform because the animal is in sitting position and surgeons can sit parallel to the camel. The paralumbar fossa is also preferred in llamas and alpacas with the animal restrained in right lateral recumbency $[30,65]$. Two techniques have been described for operation at this site a) incision (30 - $40 \mathrm{~cm}$ long) in the 
middle of the fossa $6 \mathrm{~cm}$ below the second lumbar transverse process and parallel to the last rib extending through skin, muscles and peritoneum [35,54] or b) an oblique incision in the lower flank $10 \mathrm{~cm}$ posterior to the last rib [32]. In the ventro lateral approach a skin incision (30 - $40 \mathrm{~cm}$ ) is made $5-10 \mathrm{~cm}$ above and parallel to the subcutaneous abdominal vein in an oblique fashion [34, 38]. Alternatively the incision may be just lateral to arcus cruralis and the stifle joint on the left side in dromedary camels with the animal restrained in right lateral recumbency [66]. Ventral midline laparotomy has also been suggested for cesarean section in the South American camelids but is best performed with the dam under general anesthesia [56]. After incising the skin the sub cutaneous tissues are deflected by blunt dissection, the muscle layers are cut with scissors carefully ligating all bleeding vessels. The peritoneum is grasped with tissue forceps and cut with scissors. A nick is first made and then the entire peritoneum is cut with scissors guiding with the finger. Extreme care must be exercised in cutting the peritoneum to avoid incising the spleen which is just underneath when using the paralumbar fossa as an operative site [30,54]. The uterus is grasped over the fetal part (like limb) and brought to the operative site and packed on the sides with sterile drapes. The uterus is incised along the greater curvature avoiding major vessels. The fetus is taken out and the uterus is flushed with normal saline (2 - 6 liters) and metronidazole. The uterus is sutured with Lambert sutures using catgut or other absorbable suture materials (2 or 3 number). Any ruptures on the uterus must be sutured. The uterus is placed back in the abdominal cavity. Antibiotic powder must be sprinkled and the peritoneum, muscles and subcutaneous tissue repaired. The skin is sutured using silk employing simple interrupted or interlocking sutures. The muscles and peritoneum should be sutured carefully avoiding dead space and it would be an added advantage if interrupted sutures are used.

\subsubsection{Post Operative Care and Complications}

Antibiotics and anti-inflammatory drugs are suggested to be given for 5 - 7 days along with fluids [30]. Administration of 30 - 40 IU of oxytocin may be indicated IM to stimulate uterine contractions and hasten placental expulsion [62]. The skin sutures heal with difficulty in the camel. Also, fluid accumulation at the operative site is common [26,54]. Herniation at the operative site is a common complication [34,66]. It is imperative to monitor the general condition of the patient. The first $72 \mathrm{~h}$ are critical as peritonitis often develop during this period [26]. The skin sutures must only be removed after complete healing which may take up to 20 days in the dromedary camel [54]. Less frequent complications noted in the llamas and alpacas include vaginal tears, vulvar swel- ling, metritis, retained placenta, hyperglycemia and uterine prolapse [26].

\section{TWINS IN CAMELS}

The existence of twins in camels is rare. The peculiarity of camel uterine horns is the shortness of the right uterine horn and the presence of exclusive left horn pregnancy [16]. Although ovulations can occur on either of the ovaries, but the embryo exclusively migrates from the right uterine horn to be established in the left uterine horn. Coupled with this and also because of the fact that the placenta is diffuse in camels, hence twin pregnancies can not continue due to lack of placental area for the two fetuses as observed for the equine species. However, it has been recorded that the incidence of twin births is of the order of $0.1 \%-0.4 \%$ [45]. It was also quoted that male identical twins were aborted at advanced gestation and so did the split embryos implanted in the uterus abort at mid gestation [68]. However, the same workers reported that they were able to get live births from transfer of split embryos in the camel. Contrary to this hypothesis we had observed live births of fraternal twins in dromedary camels [69] without any parturition difficulty. Thus, when twin births can occur in camels they can result in dystocia when presented simultaneously.

\section{REFERENCES}

[1] Tibary, A. and Anouassi, A. (2001) Obstetrics in camels. In: Skidmore, L. and Adams G.P., Eds., Recent Advances in Camelid Reproduction, A1005.0501

[2] Long, P. (2007) Camelid eustocia and dystocia. 79th Western Veterinary Conference, Las Vegas, 18-22 February 2007.

[3] Moldagaliev, T.M. (1975) The effect of fetal size and pelvic measurements on parturition in different species of camels. Animal Breeding Abstract, 94, 653.

[4] Elias, E. and Cohen, D. (1986) Parturition in the camel (Camelus dromedarius) and some behavioral aspects of their newborn. Comparative Biochemistry Physiology Part A: Physiology, 84, 413-419. doi:10.1016/0300-9629(86)90339-7

[5] Prakash, A. and Singh, V. (1962) Normal parturition in camels. Indian Veterinary Journal, 39, 551-553.

[6] Sharma, S.S. (1968) Studies on gestation period, birth weight, parturition and involution in the camel. MVSc Thesis, University of Udaipur, Udaipur, India.

[7] Sharma, S.S. and Vyas, K.K. (1970) Parturition in the camel (Camelus dromedarius). Ceylon Veterinary Journal, 18, 7-9.

[8] Arthur, G.H. and Al-Rahim, A.T. (1982) Aspects of reproduction in the female camel (Camelus dromedarius) in Saudi Arabia. Veterinary Medical Review, 1, 83-88.

[9] Musa, B.E. (1983) Normal parturition in the camel 
(Camelus dromedarius). Vlaams Diergeneeskundig Tijdschrift, 52, 255-268.

[10] Al-Eknah, M.M. (1996) Dilatation of the cervix during periparturient period in the camel (Camelus dromedarius). Journal of Camel Practice and Research, 3, 133-136.

[11] Johnson, L.W. (1997) Parturition in the llama. In: Youngquist, R.S., Ed., Current Therapy in Large Animal Theriogenology, WB Saunders, 813-817.

[12] Zhao, X.X. (2000) Reproduction in the Bactrian camel. In: Gahlot, T.K., Ed., Selected Topics on Camelids, Camelid Publishers, Bikaner, 499-538.

[13] Hussein, M.F., Noseir, M.B., El-Bawab, I.E. and Paccamonti, D.L. (1991) Prenatal assessment of weight and dimensions of the camel conceptus (Camelus dromedarius). Animal Reproduction Science, 26, 129-136. doi:10.1016/0378-4320(91)90071-7

[14] Arthur, G.H. (1992) An overview of reproduction in camelids. Proceedings of the first International Camel Conference, Dubai, 2-6 February 1992, 109-113.

[15] Agab, H. (2006) Diseases and causes of mortality in a camel (Camelus dromedarius) dairy farm in Saudi Arabia. Journal of Camel Practice and Research, 13, 57-61.

[16] Tibary, A. and Anouassi, A. (1997) Obstetrics and neonatal care. In: Tibary, A., Ed. Theriogenology in Camelidae. Abu Dhabi Printing Press, Mina.

[17] Lang, E.M. (1945) Embryotomy in a Guanaco in a zoo. Geburtshilfe in Zoologischen Garton. Zoologische Garten, 14, 29-32.

[18] Patterson, K. (1982) Dystocia. Llama World, 1, 113-116.

[19] Johnson, L.W. (1989) Llama medicine and nutrition. Veterinary Clinics of North America Food Animal Practice, 5, 37-54.

[20] Ordoney, T.H. (1994) Llamas, llama production and llama nutrition in the Ecuador highlands. Journal of Arid Environment, 26, 67-71. doi:10.1006/jare.1994.1010

[21] Sandoval, S. (2006) Labor and dystocia in South American camelids. Veterinary Technician, 27, 8.

[22] Bravo, P.W. (2002) The reproductive process of South American camelids. Seagull Printing, Salt Lake City, $1-31$.

[23] Rosas, G. (1979) Un cas de dystocie chezune chamelle D’Asie (Camelus bactrianus). Revue de Medicine Veterinaire, 30, 441-446.

[24] Eulenberger, K. (2000) Medical treatment of dystocia in zoo animals. Dtsch Tierarztl Wochenschr, 107, 512-515.

[25] Van Straten, M. (2000) Periparturient conditions affecting camels (Camelus dromedarius) in Israel and their treatments. Revue Elevage et de Medicine Veterinaire des Pays Tropicaux, 53, 101-104.

[26] Anderson, D. (2010) Cesarean section in alpacas and llamas: 25 cases (2000-2008). Proceedings $26^{\text {th }}$ Congress World Association of Buiatrics, Santiago de Chile.

[27] Al-Eknah, M.M., (2001) Camels. In: Noakes, D.A., Parkinson, T.J. and England, G.C.W., Eds., Arthur's Veterinary Reproduction and Obstetrics, WB Saunders, London, 781-788.
[28] Paul-Murphy, J. (1989) Obstetrics, neonatal care and congenital condition. Veterinary Clinics of North American Food Animal Practice, 5, 183-202.

[29] Hopkins, S.M., Althouse, G.C., Jackson, L.L. and Evans, L.E. (1991) Surgical treatment of uterine torsion in a llama (Lama glama). Cornell Veterinarian, 81, 425-428.

[30] Anderson, D.E. (2009) Uterine torsion and cesarean section in llamas and alpacas. Veterinary Clinics of North America Food Animal Practice, 25, 523-538. doi:10.1016/j.cvfa.2009.02.002

[31] Petris, M.A. (1956) Caesarean operation in camels. Veterinary Record, 68, 374-376.

[32] Nigam, J.M., Gupta, R.C., Khar, S.K., et al. (1977) Torsion of the uterus in a camel. The Haryana Veterinarian, 116, 33-36.

[33] Frerking, H. and Andreson, A. (1978) Schnittentbin dung bei einer Drome darstute mit prazervickaler torsio uteri (clinical short communication). Der Prakitsche Tierarzt, 128-129.

[34] Elias, E. (1991) Left ventrolateral cesarean section in three dromedary camels (Camelus dromedarius). Veterinary Surgery, 20, 323-325. doi:10.1111/j.1532-950X.1991.tb01277.x

[35] Sharma, D.K. and Pareek, P.K. (1970). Clinical communication: Caesarean section in a camel. Ceylon Veterinary Journal, 18, 7-9.

[36] Saltet, J., Dart, A.J., Dart, C.M. and Hodgson, D.R. (2000) Ventral midline cesarean section for dystocia secondary to failure to dilate the cervix in three alpacas. Australian Veterinary Journal, 78, 326-328. doi:10.1111/j.1751-0813.2000.tb11782.x

[37] Tibary, A., Rodriguez, J.S., Anouassi, A. and Walker, P. (2008) Management of dystocia in camelids. Proceedings of $41^{\text {st }}$ Annual Conference of American Association of Bovine Practitioners, Charlotte, 25-27 September 2008, 166-176.

[38] Jones, M. (2009) Obstetrics and post dystocia care of camelid dams. Cental Veterinary Conference, Kansas City, 1 August 2009, 1-3.

[39] Cebra, C.K., Cebra, M.L., Garry, F.B., and Johnson, L.W. (1997) Surgical and non-surgical correction of uterine torsion in new world camelids: 20 cases (1990-1996). Journal of American Veterinary Medical Association, 211, 600-602.

[40] Purohit, R.K., Chauhan, D.S. and Purohit, N.R. (1982) Ventral hernia in camel (Camelus dromedarius) and its treatment by herniorrhapy. Indian Journal of Veterinary Surgery, 3, 106-107.

[41] Tank, P.H., Dabas, V.S., Patil, D.B. and Ojha, S.C. (1996) Repair of recurrent abdominal hernia by hernioplasty in a camel. Journal of Camel Practice and Research, 3, 149.

[42] Ramadan, R.O. and Abdin Bey, M.R. (2001) Abdominal and inguinal hernias in camel (Camelus dromedarius) in Saudi Arabia (field cases). Emirates Journal of Agricultural Science, 13, 57-61.

[43] Vyas, S., Sharma, N., Bissa, U.K., Chirania, B.L. and Bishnoi, B.L. (1999). Effect of prostaglandin $F_{2}$ alpha on 
induction of parturition in she camel. Indian Journal of Animal Reproduction, 20, 73.

[44] Bennett, J., Kennel, A. and Stanhope, C.R. (1998) Surgical correction of an acquired vaginal stricture in a llama using a carbon dioxide laser. Journal of American Veterinary Medical Association, 212, 1436-1437.

[45] Arthur, G.H., Noakes, D.E., Pearson, H. and Parkinson, T.J. (1999) Reproduction in the camel. In: Arthur, G.H., Noakes, D.E., Pearson, H. and Parkinson, T.J., Eds., Veterinary Reproduction and Obstetrics, WB Saunders, London, 659-666.

[46] Gera, K.L. and Datt, S.C. (1981) Fetal dystocia in a she camel. A case report. Indian Veterinary Journal, 58, 6465.

[47] Sharma, L.K. (1992) A case report on dystocia in camel (Camelus dromedarius). Indian Veterinary Journal, 69, 931-932.

[48] Sumar, J. (1985) Some aspects of obstetrics of the alpaca. Alguinos aspectos obstetrics de la alpaca. Bobtim Tecnico, 2, 245.

[49] Fowler, M.E. (1989) Medicine and surgery of South American camelids. Ames. Iowa state University Press, Iowa.

[50] Gabra, H.S. (1993) Teratology-A monstrous fetus in a one humped camel (Camelus dromedarius). Camel Newsletter, ASCAD, 17-19.

[51] Chandolia, R.K., Sharma, D.K., Singh, P. and Verma, A.K. (1991) Fetal monstrosity in a Bikaneri camel (Camelus dromedarius). Indian Journal of Animal Reproduction, 12, 108-110.

[52] Sonfada, M.L., Shehu, S.A., Umar, A.A. and Onyeanusi, B.I. (2009) Anencephaly in a second trimester camel foetus in Sokoto, Nigeria: A case report. Journal of Camelid Science, 2, 50-52.

[53] Abubakr, M.I., Ahmed, A.A. and Nayel, N.M. (1998) Hydrocephalus in a new born male camel calf. Journal of Camel Practice and Research, 5, 309.

[54] Purohit, G.N., Mehta, J.S., Garg, N., Vyas, K., Gupta, A.K., Pareek, P.K. and Sharma, S.S. (2000). Caesarean section in a dromedary camel a case report. Indian Journal of Animal Reproduction, 1, 76-77.

[55] Purohit, G.N. and Pareek, P.K. (2000) Research on dromedary reproduction-The past two decades and future prospective. Veterinary Bulletin, 70, 1265-1274.

[56] Fowler, M.E. (1998) Medicine and surgery of South American camelids: Llama, alpaca, vicuna, guanaco. Iowa State University Press, Iowa.
[57] Rathore, S.S. (1962) Cesarean operation in camels. Indian Veterinary Journal, 39, 42-44.

[58] Sharma, D.K., Behl, S.M., Khanna, B.M., et al. (1982) Use of xylazine as anesthetic in cesarean in a camel. Haryana Veterinarian, 21, 50-51.

[59] Purohit, N.R., Chauhan, D.S., Purohit, R.K. and Chaudhary, R.J. (1985) Cesarean section in a camel. Agriculture Practice, 26, 28-29.

[60] Bolbol, A.E., Hassanein, A. and Ibrahim, H. (1980) Some investigations in the camel after sedation with Rompun (xylazine). Veterinar Medizinische Nachrichten, 1, 55-60.

[61] Ali, B.H., El Sanhouri, A.A. and Musa, B.E. (1989) Some clinical, haematological and biochemical effects of four tranquilizers in camels (Camelus dromedarius). Revue Elevage Medicine Veterinaire et de Pays Tropicaux, 42, 13-17.

[62] Tibary, A. and Anouassi, A. (2000) Surgery of the reproductive tract in camels. In: Skidmore, J.A. and Adams, G.P., Eds., Recent Advances in Camelid Reproduction, A.1008.1100.

[63] Grubb, T.L., Reibold, T.W. and Huber, M.J. (1993) Evaluation of lidocaine, xylazine and a combination of lidocaine and xylazine for epidural analgesia in llamas. Journal of American Veterinary Medical Association, 203, 1441.

[64] Waldridge, B.M., Hui-Chu, L. and De Graves, F.J. (1997) Sedative effects of metdetomidine and its reversal in llamas. Journal of American Veterinary Medical Association, 211, 1562-1565.

[65] Anderson, D.E. (1999). Common surgical procedures in camelids. Journal of Camel Practice and Research, 6, 191-201.

[66] Purohit, G.N., Mehta, J.S., Dholpuria, S., Kumar, P., Yadav, S.P. and Shekher, C. (2011) Dystocia in dromedary camels: Handling and outcome of eleven cases. Theriogenology Insight, 1, 15-23.

[67] Purohit, N.R., Chauhan, D.S. and Chaudhary, R.J. (1989) Post cesarean ventral hernia in two camels. British Veterinary Journal, 145, 294. doi:10.1016/0007-1935(89)90084-5

[68] Tinson, A.H., Kuhad, K.S., Singh, K., Sambyal, R., Mugheiry, A., Rahman, A. and Al-Masri, J. (2001) Twinning in camels. Emirates Journal of Agricultural Science, 13, 17-73.

[69] Purohit, G.N. (1999) Fraternal dromedary twins. A case report. Journal of Camel Practice and Research, 6, 123. 